\section{Conquistas e desafios no atendimento das mulheres que sofreram violência sexual}

\author{
Advances and challenges in treatment for \\ female victims of sexual violence
}

\footnotetext{
${ }^{1}$ Escola Paulista de Medicina, Universidade Federal de São Paulo, São Paulo, Brasil.

2 Faculdade de Medicina Santa Casa da Misericórdia de São Paulo, São Paulo, Brasil.

Correspondência W. V. Villela

Departamento de Medicina Preventiva, Escola Paulista de Medicina, Universidade Federal de São Paulo. Rua Borges Lagoa 1341, São Paulo, SP

04038-034, Brasil. wilsa.vieira@terra.com.br
}

\begin{abstract}
This article analyzes treatment for female victims of sexual violence, with a focus on partnerships between government and the organized women's movement. The central references are the specific literature and testimony by key social actors who have participated in this process. The results show that despite the real and symbolic importance of care for rape victims, the government and the women's movement have not succeeded in guaranteeing the expansion of these services or adequately linking the discussion of sexual violence to women's right to abortion under any circumstances. It is thus necessary to step up the measures on this agenda.
\end{abstract}

Sexual Violence; Health Policy; Legal Abortion
Wilza V. Villela ${ }^{1}$

Tânia Lago 2

\section{Introdução}

O revigoramento do movimento feminista na década de 60 traz para o debate público temas até então referidos ao âmbito privado, como a sexualidade e os usos dos corpos das mulheres, demandando que o Estado, por meio de suas políticas, incorpore as reivindicações das mulheres. Dentre estas, aparece como prioritária a questão da violência.

Como resposta, em 1985 começam a ser criadas as primeiras delegacias de Atendimento Especializado à Mulher (DEAM), no âmbito da Segurança Pública, buscando criar uma instância específica para acolher as denúncias de violência por parte das mulheres.

No setor saúde, embora a diretriz de assistência integral às mulheres exija que seja contemplada a interface entre violência de gênero e saúde, a resposta é mais tardia, e são necessários nove anos desde a criação do primeiro serviço de atendimento às vítimas de violência sexual para que o Estado estabeleça as normas para implantação e funcionamento deste tipo de serviço.

Em 1999, a Norma Técnica para Prevenção e Tratamento dos Agravos Resultantes da Violência Sexual contra Mulheres e Adolescentes 1 , do Ministério da Saúde, lança as bases operacionais da política de atendimento a mulheres e adolescentes que sofreram violência sexual, estimulando a criação, no âmbito do Sistema Único de Saúde (SUS), de serviços de atendimento às mulheres 
violentadas e redes de referência que facilitem o acesso das mulheres a estes equipamentos.

No entanto, a estruturação e manutenção destes serviços e redes não têm sido uma tarefa simples, exigindo continuados esforços de articulação técnica e política. Desta forma, o número de serviços de saúde capacitados a realizar todos os procedimentos previstos na norma técnica, incluindo a interrupção da gravidez, quando é o caso, é insuficiente para o tamanho do país; mesmo onde há serviços, muitas mulheres ainda encontram dificuldades para serem atendidas 2 .

\section{Violência sexual e saúde}

A violência sexual, praticada sob forma de abuso (ato sexual entre um adulto e uma criança), estupro (conjunção carnal forçada por meio de violência), ou do atentado violento ao pudor (prática de ato libidinoso diverso da conjugação carnal mediante coerção), ocorre em todos os tipos de sociedade, e afeta pessoas de qualquer idade, classe social e etnia. Os autores da violência sexual podem ser conhecidos, desconhecidos e mesmo familiares. No caso da violência contra mulheres, com muita freqüência os autores são os parceiros, maridos ou namorados 3 .

É difícil estimar a magnitude da violência sexual. As vítimas tendem a silenciar sobre o assunto, seja por medo de represália, quando o autor é familiar ou conhecido, vergonha, sentimentos de humilhação e culpa, já que persiste no imaginário social, e mesmo entre os profissionais de saúde que atendem em serviços de emergência, a idéia de que a mulher é culpada pela violência sofrida 4 . Apesar desta dificuldade, e considerando apenas os casos registrados em bancos de dados policiais, a Organização Mundial da Saúde (OMS) aponta para uma prevalência de estupro entre 2 e $5 \%$, nos diferentes países do mundo 5 .

A violência sexual pode acarretar diversos problemas de saúde para a mulher, tanto imediatamente após o evento quanto a médio e longo prazo. Nestes casos podem ser citadas queixas físicas, como cefaléia crônica, alterações gastrointestinais, dor pélvica, e outras, ou sintomas psicológicos e comportamentais, como disfunção sexual, depressão, ansiedade, transtornos alimentares/obesidade e o uso abusivo de drogas 6 .

Dentre as conseqüências imediatas da violência para a saúde das mulheres, devem ser consideradas as infecções do trato reprodutivo, incluindo a infecção pelo HIV, e a chance de gravidez.

\section{A implementação dos serviços de atendimento às mulheres vítimas de violência sexual}

A implantação das DEAM significa o reconhecimento, por parte do Estado, de que a violência contra as mulheres não é uma questão a ser abordada como um problema da esfera privada ou das relações interpessoais, mas é um problema social que exige, para o seu enfrentamento, ações públicas no âmbito da segurança e do direito como também da saúde, pelas seqüelas que produz.

Em relação à violência sexual, que articula significados culturais, éticos e morais relacionadas tanto às relações entre homens e mulheres quanto à sexualidade, a ação pública deve incidir sobre três dimensões: no nível das mentalidades, pela afirmação de que a violência sexual é um crime e que a mulher violentada não é culpada ou responsável pela sua ocorrência, de modo a romper com a banalização e a naturalização deste delito, facilitando que a mulher o reconheça como tal e procure ajuda, sem medo ou vergonha; na organização de sistemas formais de vigilância e notificação de crimes sexuais de modo a acolher e encaminhar as denúncias e dar visibilidade a este agravo; na estruturação de uma rede de assistência articulando serviços de saúde e de segurança pública de modo a garantir atendimento imediato às vitimas e prevenir problemas de saúde a médio e longo prazo. Neste atendimento imediato devem ser consideradas as ações para evitar que do estupro resulte uma gravidez, como também a interrupção de uma eventual gravidez, em casos de falha ou da impossibilidade de realização da contracepção de emergência.

O Código Penal brasileiro não considera crime a interrupção de uma gestação decorrente do estupro. No entanto, até 1990, este permissivo legal não havia sido utilizado, nem feita qualquer regulamentação no sentido de incorporar a realização do aborto, nestes casos, como uma ação de saúde a ser ofertada pelo Estado. Esta omissão possivelmente esteve relacionada à forte rejeição social ao aborto, baseada em preceitos morais e religiosos 7, à invisibilidade de violência sexual, e às atribuições culturais relativas à sexualidade, que tendem a transformar as vítimas em rés, pela insinuação da que muitas mulheres "provocam" os homens com sua beleza ou sensualidade, e que a sexualidade masculina é "incontrolável" 8. Assim, a organização de um modelo adequado de atendimento às vítimas de violência sexual implicava, por um lado, a discussão política da questão da violência contra as mulheres, e por outro, a abordagem ética e moral da questão do aborto. 
É neste contexto que se articulam agentes governamentais dos setores de saúde, segurança pública e do poder judiciário, movimento de mulheres representado pela Rede Nacional Feminista de Saúde e Direitos Reprodutivos e Sexuais e a Federação Brasileira de Ginecologia e Obstetrícia (FEBRASGO) visando sensibilizar a opinião pública a respeito do problema, garantir suporte social e político e estabelecer as bases técnicas para atendimento de mulheres que sofreram violência sexual, incluindo a interrupção da gravidez ${ }^{9}$.

O primeiro serviço de atendimento a vítimas de violência sexual foi implantado na cidade de São Paulo, no Hospital Municipal do Jabaquara, em 1990, fruto do esforço conjunto dos atores sociais acima referidos e da direção do hospital. Fluxos e rotinas foram amplamente discutidos, assim como foram realizados treinamentos específicos, visando capacitar a equipe para os procedimentos médicos e de enfermagem, o apoio psicossocial e para a reflexão a respeito de temas como gênero e violência 10 .

Entre 1990 e 1994, o Hospital Municipal do Jabaquara foi o único serviço do SUS a realizar a interrupção da gravidez nos casos de violência sexual. Em 1994, em decorrência das recomendações da Conferência Internacional sobre População e Desenvolvimento, da qual o governo brasileiro foi signatário, de que os países deveriam garantir a assistência ao abortamento nos casos previstos em lei e melhorar a qualidade da assistência ao abortamento em geral 11, mais um serviço é organizado na cidade de São Paulo, dentro do Hospital Estadual Pérola Byington. Nos anos subseqüentes, alguns outros serviços são inaugurados, sempre envolvendo a parceria governo local, FEBRASGO e movimento feminista. No entanto, o grande aumento de serviços de atendimento às mulheres vítimas de violência ocorre a partir de 1999, quando o Ministério da Saúde edita a Norma Técnica para Prevenção e Tratamento dos Agravos Resultantes da Violência Sexual contra Mulheres e Adolescentes.

\section{A construção da norma técnica e a expansão da rede de atendimento a vítimas de violência sexual}

Em 1996, ocorreu a recomposição da Comissão Intersetorial da Saúde da Mulher (CISMU), instância assessora do Conselho Nacional da Saúde ao ser rearticulada passa a contar com uma forte presença de feministas e com a representação da FEBRASGO. Por meio de uma negociação interna entre a CISMU e representantes do Ministério da Saúde foi proposta a elaboração de uma nor- ma técnica para a implementação de serviços de atendimento à violência sexual que incluísse o aborto. Após discussão no Conselho Nacional de Saúde, a proposta foi aprovada e encaminhada à Área Técnica de Saúde da Mulher, para ser implementada.

Em 2004, a Área Técnica da Saúde da Mulher do Ministério da Saúde convoca os mesmos atores para elaborar uma proposta de atualização da norma técnica, provocando um grande debate com o Conselho Federal de Medicina, no que toca à necessidade do Boletim de Ocorrência para a realização do aborto.

A norma técnica, resultado de um esforço coletivo de diferentes setores da sociedade, tem sido um instrumento fundamental para que o tema da violência sexual seja definitivamente incorporado pelo setor saúde e para que a sociedade começasse a discutir a questão do aborto de um modo mais amplo.

Em 2002 existiam 245 serviços de saúde capacitados a atender mulheres vítimas de violência sexual 12, na sua grande maioria serviços ambulatoriais que não poderiam realizar o aborto, quando necessário. Segundo o Ministério da Saúde, em 2002 havia 39 hospitais com este tipo de serviço implantado, e dez já haviam sido capacitados para entrar em atividade. No entanto, pesquisa realizada em 20022 aponta que apenas 37 hospitais confirmaram prestar este tipo de atendimento, sendo que destes, cinco nunca haviam realizado algum procedimento. A maioria dos serviços exige boletim de ocorrência para fazer o atendimento e alguns hospitais exigem também laudo do Instituto Médico Legal.

Os serviços estão concentrados na região sudeste e cinco estados da federação ainda não contam com nenhum serviço de atendimento a vítimas de violência sexual; a pesquisa mostra que até hoje foram realizadas 1.266 interrupções de gravidez em decorrência de estupro.

A análise desses dados merece algumas reflexões: em primeiro lugar, chama atenção o número relativamente pequeno de interrupções de gravidez decorrentes do estupro, considerandose, por exemplo, que entre 2001 e 2003 foram registrados 43.227 casos de estupro no país 13 . Ou seja, apenas uma pequena proporção das mulheres que notificaram o estupro precisou e obteve a interrupção legal da sua gravidez. Pode-se considerar que esta desproporção em parte esteja relacionada à insuficiência numérica dos serviços e outras barreiras de acesso às mulheres. Também não se pode descartar a efetividade da contracepção de emergência, que é disponibilizada quando a mulher consegue acessar o serviço de saúde a tempo de receber este benefício. 
Ao mesmo tempo, pesquisa da Universidade Federal de São Paulo, realizada em três hospitais públicos na cidade de São Paulo que atendem casos de violência sexual, aponta que de um total de 8.600 atendimentos realizados entre 1998 e 2003, apenas cerca de $10 \%$ das vítimas haviam dado queixa à polícia 14 . Ou seja, parece que onde existem serviços de saúde as mulheres preferem recorrer a este tipo de equipamento, ao invés de buscar os serviços da polícia, o que sugere a necessidade imediata da expansão dos serviços de saúde que atendem mulheres violentadas, como também da maior integração entre saúde e segurança pública. De fato, a experiência tem demonstrado que uma boa integração entre os serviços de saúde e de segurança pública é essencial para garantir integralidade, qualidade e resolutividade da atenção 15 .

\section{Atuais desafios}

Apesar do enorme avanço que representou a norma técnica, a garantia de acesso das mulheres que sofreram violência sexual a um atendimento integral e de qualidade ainda representa um desafio. A expansão da rede de atenção, por exemplo, depende da vontade política do gestor local, que muitas vezes teme perder votos ou apoio político de setores mais conservadores caso adote uma política que ainda não goza de uma plena aceitação. De fato, ao longo destes anos não foram poucos os embates com os setores conservadores da sociedade em torno da implementação da norma técnica, especial no que diz respeito à realização do aborto. Em 2005, por exemplo, quando da atualização da norma, gerou-se uma grande polêmica em torno da exigência de boletim de ocorrência. Segundo alguns, as mulheres poderiam mentir sobre o fato de terem sido violentadas apenas para fazer um aborto. Mais uma vez, a ação articulada de representantes do movimento feminista e da FEBRASGO contribuiu para que estas opiniões não fizessem retroceder a norma. No entanto, o eventual desgaste que representa, para um governo local, este tipo de enfrentamento, tem contribuído para limitar a expansão dos serviços.

Ao mesmo tempo, alguns profissionais de saúde relutam em pressionar seus chefes de serviço para implantar o atendimento às vítimas temendo serem identificados como defensores do aborto ou "aborteiros" 11.

A integração com o setor de segurança pública, embora seja essencial para facilitar o acesso das vítimas ao atendimento em saúde e à abertura do inquérito policial, também não ocorre de forma fácil e sem conflitos. Ainda não existe uma sistemática ampla e regular de capacitação destes profissionais em questões de violência de gênero, o que faz com que muitos deles atuem frente às vítimas de forma preconceituosa ou até mesmo discriminadora. As DEAM, depois de experimentarem uma expansão inicial, durante muito tempo deixaram de ser objeto de investimento por parte dos governos e só recentemente estão passando por um processo de renovação que significa a necessidade permanente de uma sensibilização e educação continuada dos diferentes profissionais que atuam nesta área.

A ampliação da pauta do movimento feminista, problemas de financiamento de algumas organizações não-governamentais e mesmo a migração de alguns quadros do movimento para espaços de governo têm dispersado parte da energia que entre 1998 e 2002 esteve concentrada na discussão e mobilização social para a implementação deste tipo de serviço. Assim, seria necessário um reposicionamento político por parte da militância feminista de modo a reintroduzir na pauta o monitoramento da implementação da norma técnica.

A discussão do atendimento a vítimas de violência sexual constitui um paradoxo para o setor saúde, pois articula um tema (a violência), cuja interface com a saúde é de reconhecimento recente, com duas práticas muito antigas e prenhes de significações morais, éticas e religiosas: a violação do corpo das mulheres e a prática do aborto. Enfrentar este paradoxo, garantindo às mulheres o direito à saúde e à autonomia sobre seus corpos é uma tarefa que, sem dúvida, exige um esforço contínuo, integrado dos diferentes setores da sociedade. 


\section{Resumo}

Este artigo analisa o atendimento à saúde de mulheres que sofreram violência sexual, tendo como foco a parceria entre governo e movimento organizado de mulheres. Toma como referência a bibliografia específica e o depoimento de alguns atores sociais que participaram desta construção. Os resultados mostram que apesar da importância, real e simbólica, do atendimento às vítimas de violência sexual, governo e movimento de mulheres não têm conseguido garantir a expansão destes serviços, nem articular a contento a discussão sobre a violência sexual e o direito das mulheres ao aborto em quaisquer condições, sendo necessário intensificar as ações em torno desta pauta.

Violência Sexual; Políticas de Saúde; Aborto Legal

\section{Colaboradores}

Ambas as autoras participaram de todo processo do artigo.

\section{Referências}

1. Ministério da Saúde. Norma técnica prevenção e tratamento dos agravos resultantes da violência sexual contra mulheres e adolescentes. Brasília: Ministério da Saúde; 1999.

2. Talib RA, Citeli T. Serviços de aborto legal em hospitais públicos brasileiros (1989-2004). Cadernos Católicos pelo Direito de Decidir 2005; 13:12-3.

3. Freitas OS. Violência sexual. http://www.portaldeginecologia.com.br (acessado em 30/Jun/2006).

4. Cavalcanti LF, Gomes R, Minayo MCS. Representações sociais de profissionais de saúde sobre violência sexual contra a mulher: estudo em três maternidades públicas municipais do Rio de Janeiro, Brasil. Cad Saúde Pública 2006; 22:31-9.

5. Krug EG, Dahlberg LL, Mercy JA, Zwi AB, Lozano R, editors. World report on violence and health. Geneva: World Health Organization; 2002.

6. Marcussi A. Fatores associados ao uso abusivo de substâncias psicoativas: história de abuso e negligência na infância, história familiar e co-morbidades psiquiátricas [Tese de Doutorado]. São Paulo: Programa de Pós-graduação em Psicobiologia, Universidade Federal de São Paulo; 2005.

7. Rosado-Nunes MJ. Aborto, maternidade e a dignidade das mulheres. In: Cavalcanti A, Xavier D, organizadores. Em defesa da vida: aborto e direitos humanos. São Paulo: Católicas pelo Direito de Decidir; 2006. p. 23-39.

8. Villela W, Barbosa R, Uziel AP. Entre a vontade e a necessidade: a construção diferenciada do sexo entre homens e mulheres. Physis (Rio J) 1995; 5: 99-107.
9. Villela WV, Araujo MJO. Making legal abortion available in Brazil: partnerships in practice. Reprod Health Matters 2000; 8:77-82.

10. Castanheira ER. Boas práticas em gestão de saúde reprodutiva: o serviço de aborto legal do Hospital Municipal do Jabaquara. São Paulo: Faculdade de Medicina, Universidade de São Paulo; 2000.

11. Soares GS. Profissionais de saúde frente ao aborto legal no Brasil: desafios, conflitos e significados. Cad Saúde Pública 2003; 19 Suppl 2:S399-406.

12. Lago TG. La participación ciudadana en la toma de decisiones con respecto a la salud de la mujer en Brasil. In: Nigenda G, Langer A, López-Ortega M, Troncoso E, organizadores. Procesos de reforma del sector salud y programas de salud sexual y reproductiva en América Latina. México DF: Fundación Mexicana para la Salud; 2004. p. 45-72.

13. Secretaria Nacional de Segurança Pública, Ministério da Justiça. Sistema nacional de estatística de segurança pública e justiça criminal. http://www. mj.gov.br/senasp/estatisticas/estat_ocorrencia. htm (acessado em 01/Jul/2006).

14. Oliveira EM, Barbosa RM, Moura AA, von Kossel K, Botelho LF, Stoianov M. Atendimento às mulheres vítimas de violência sexual: um estudo qualitativo. Rev Saúde Pública 2005; 39:376-82.

15. Campos MAMR, Schor N, Anjos RMP, Laurentiz JC, Santos DV, Peres F. Violência sexual: integração saúde e segurança pública no atendimento imediato à vítima. Saúde Soc 2005; 14:101-9.

Recebido em 31/Ago/2006 Aprovado em 06/Set/2006 